\title{
Less typical form and less typical clinical picture of atrial wall subacute perforation with atrial lead
}

\author{
Jakub Zawadzki ${ }^{1}$, Marcin Grabowski ${ }^{1}$, Marek Czajkowski², Andrzej Tomaszewski ${ }^{3}$, Andrzej Kutarski ${ }^{3}$ \\ A - Research concept and design, B - Collection and/or assembly of data, C - Data analysis and interpretation, \\ D - Writing the article, E - Critical revision of the article, F - Final approval of article
}

1 1st Department of Cardiology, Medical University of Warsaw

2 Department of Cardiac Surgery Medical University of Lublin

3 Department of Cardiology, Medical University of Lublin,

Address for correspondence:

Jakub Zawadzki, 1st Department of Cardiology, Medical University of Warsaw email: zawadzkijakub@o2.pl

\begin{abstract}
Marcin Grabowski, 1st Department of Cardiology, Medical University of Warsaw email: marcin.grabowski@wum.edu.pl
\end{abstract}

Marek Czajkowski, Department of Cardiac Surgery Medical University of Lublin email: mczajkowski@interia.pl

Andrzej Tomaszewski, Department of Cardiology, Medical University of Lublin email: ajtom@wp.pl

Andrzej Kutarski, Department of Cardiology, Medical University of Lublin email: a_kutarski@yahoo.com

Received: 13.12 .2016

Revised: 19.12.2016

Accepted: 23.12.2016

\section{Key words:}

pacemaker, atrial perforation, subacute perforation

A 37-year- old woman had undergone implantation of a permanent pacemaker (DDDR) due to a vasovagal response syndrome (VVS). The procedure went without perioperative complications. Neither the pacing control parameters nor the control chest X-ray detected abnormalities. After less than a month, the patient presented to the emergency department with complaints of chest pain intensifying during deep breathing, fatigue and breathlessness. Chest X-ray, electrocardiography (ECG), transthoracic echocardiogram (TTE) and pacemaker interrogation did not reveal any abnormalities. Therefore the patient was discharged from the hospital with the suggestion to undergo a thorough psychiatric medical examination. After a month of her own research, the patient went to the hospital with her own proper diagnosis and was referred to a cardiology department because of persistent symptoms and onset of shoulder and jaw pain. Results of tests carried out in the department showed various abnormalities. In laboratory tests, decreased levels of red blood cells (RBC) of $3.66 \times 1012 / \mathrm{L}$, hemoglobin $(\mathrm{Hb})$ of $103 \mathrm{~g} / \mathrm{L}$, and hematocrit (Hct) of 0.30 and a markedly elevated value of C-reactive protein (CRP) of $16434 \mathrm{mg} / \mathrm{L}$ (at the standard value of 0 to $5000 \mathrm{mg} / \mathrm{L}$ ) were observed. TTE (fig. 1). Also, transesophageal echocardiography (TEE) showed moderate

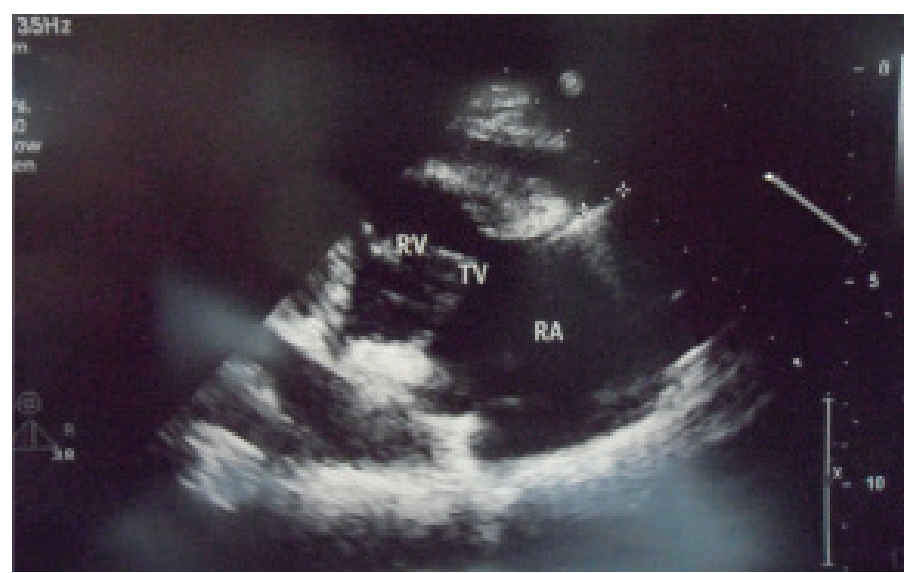

Figure 1 Pacemaker wire perforating the right antrum; also note moderate sized pericardial effusion.

pericardial effusion $(1.5 \mathrm{~cm})$ around the cardiac apex and revealed pericardial perforation of the right atrial appendage 
(RAA) caused by the atrial pacing lead. Additionally, device interrogation unmasked impedance disturbances on the atrial lead. The bipolar mode of the lead has an impedance value of $480 \mathrm{ohms}$ and unipolar $220 \mathrm{ohms}$. In view of this, the decision was made to remove and replace both pacing leads with Cook Medical device. (Figs. 2, 3).

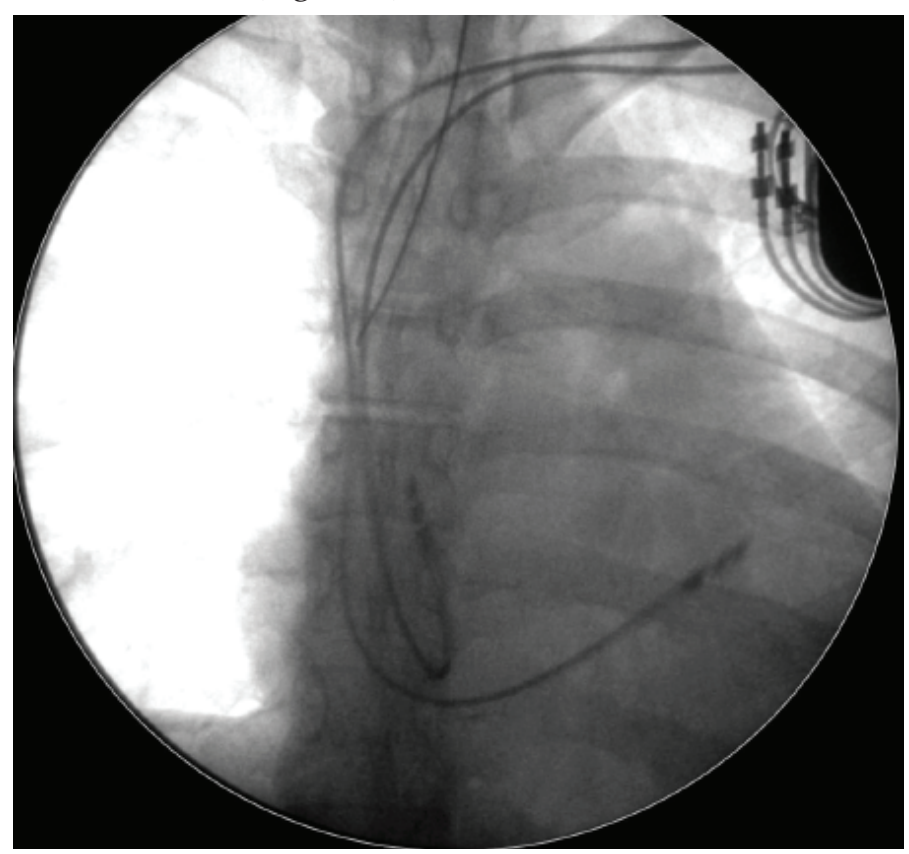

Figure 2 Fluoroscopy before removing the pacing leads.

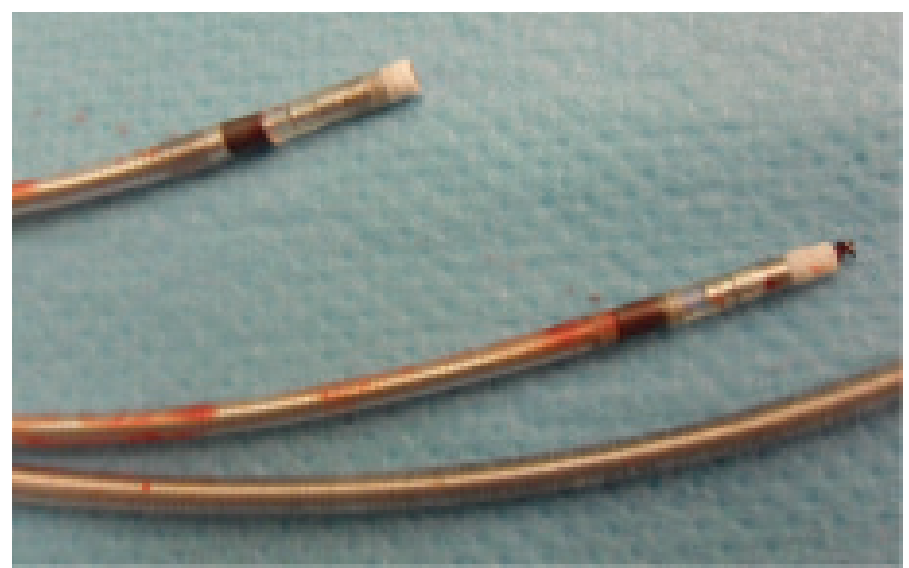

Figure 3 Removed leads.

\section{Discussion}

Cardiac perforation is an infrequent, but potentially fatal, and hence one of the most serious complications of pacemaker implantation. Perforations can be classified as acute (5-7 days after device implantation), subacute (7-30 days) and late or delayed (more than 30 days). According to published data, implantation of a pacemaker is associated with a risk of heart perforation of $0.1-1.2 \%$ or even lower $(0.06 \%$ for non-early perforation $)^{[1]}$. Perforation as a subacute complication is even rarer, but reported ${ }^{[2]}$. However, it is difficult to determine how many subacute perforations have become delayed perforations, because of the lack of a proper diagnosis. Chest X-ray is diagnostically uncertain and should be supplemented by echocardiography and pacemaker interrogation. TTE usually provides clear visualization of wires and possible pericardial effusion. But in our case placement of lead wires on X-ray as well as TTE and ECG seemed to be proper, despite onset of the patient's symptoms. ECG and pacemaker interrogation changes could be unobtrusive and not easily noticed. However, low value of impedance in the unipolar mode should suggest the possibility of perforation to the pericardium. Furthermore, it seems that despite the great importance of diagnostic echocardiography, it is not sufficient in the period preceding and in the early beginnings of RAA perforation ${ }^{[3]}$, probably because of difficulties in visualizing the boundaries of the right atrium area. Worth noting is the removal of the two pacing leads. The procedure was performed in order to exclude the possibility that, the patient's symptoms could be caused by the left lead. Also interesting is the fact that, despite the elevated level of CRP, the patient in the 2 years follow-up have not developed neither endocarditis nor pericarditis. Nevertheless, both the chest pain and fluid in the pericardium, after the pacemaker implantation should always be suspected of perforation and should be the basis for an accurate diagnostic process. Also it is worth noting that the atrial wall perforation, unlike ventricle area, could be better imaged by TEE than TTE. Finally, we should pay attention to atypical "high" pains in arms and the jaw as a possible symptom of right atrium perforation.

\section{References}

1. Lin Y-S, Chen T-H, Hung S-P, Chen DY, Mao C-T, Tsai $\mathrm{M}-\mathrm{L}$, et al. Impact of pacemaker lead characteristics on pacemaker related infection band heart perforation: a nationwide population-based cohort study. PLoS ONE (2015) 10(6): e0128320. doi:10.1371/journal. pone. 0128320

2. J. Nichols, N. Berger, P. Joseph, D. Datta. Subacute right ventricle perforation by pacemaker lead presenting with left hemothorax and shock. Case Reports in Cardiology, vol. 2015, Article ID 983930, 4 pages, 2015. doi:10.1155/2015/983930

3. M. Sterlinski, A. Przybylski, A. Maciag, P. Syska, M. Pytkowski, M. Lewandowski, et al.. Subacute cardiac perforations associated with active fixation leads. Europace (2009) 11, 206-212 doi:10.1093/europace/eun363 